Article

\title{
The Interaction and Convergence of the Philosophy and Science of Information
}

\author{
Kun Wu \\ International Center for the Philosophy of Information, Xi'an JiaoTong University, Xi'an 710048, China; \\ WuKun@mail.xjtu.edu.cn
}

Academic Editor: Marcin J. Schroeder

Received: 3 August 2016; Accepted: 21 November 2016; Published: 1 December 2016

\begin{abstract}
Under the impact of information technology and the information sciences, major changes are occurring in both science and philosophy that constitute an informational turn. The recently developed Philosophy of Information has integrated the unique dualistic ontological properties of information, and scientific rationality can now be seen to include an interactive relationship between science and philosophy. Information, in particular Information Science is thus part of the structure, and not just of the content, of philosophy. In this mode of knowledge development, science transforms philosophy and philosophy can critique both science and itself. I see a process of convergence taking place that is leading to a Unified Science-Philosophy of Information, a system of disciplines of which the Philosophy of Information is a part, and Information Science achieves an additional dimension based on this fundamental philosophical stance. I argue further that a proper new Philosophy of Science would be an informational metaphilosophy in that a Unified Science-Philosophy of Information includes both a new content of Science and new dynamics of the relations between a science and its philosophy.
\end{abstract}

Keywords: convergence; informational turn; interaction; philosophy of information; philosophy of science; Unified Science of Information; universal rationality

\section{Introduction}

The rapid expansion of the information sciences after emerging from the domain of communication has raised many philosophical questions about the nature of information and its mode of existence. Although involving the transfer of energy in some way, information is a unique complex of energy and meaning. A philosophy of information thus requires inclusion of or reference to the energetic, accordingly scientific aspects of information generation, transfer and reception. The approach I have taken is to start from the assumptions of philosophy as they were understood in the last quarter of the 20th Century and see what the implications are of the properties of information for a proper discussion of information science, philosophy and their relation.

One objective of this paper is to find an appropriate framework and language in which philosophy and the sciences, including standard Information Science can be discussed together. As we will see, information needs to be part of the structure, not just content, of philosophy itself. Concepts of information as a complex process rather than data can be applied to philosophy and assist in the understanding of it. The major problem addressed is to properly characterize the changes that are taking place in knowledge as a whole. These movements, I suggest, can be described as a convergence leading to a Unified Science-Philosophy of Information, a system of disciplines of which the Philosophy of Information is a part, and Information Science achieves an additional dimension based on this fundamental philosophical stance. I argue further that a proper new Philosophy of Science would be an informational metaphilosophy in that a Unified Science-Philosophy of Information includes both a new content of Science and new dynamics of the relations between a science and its philosophy. 
To anchor my theory in philosophy, I will start with one of the basic topics in philosophy, the question of existence.

\subsection{The Question of Existence}

In a most general sense, at the heart of knowledge is a philosophy of Being, a metatheory of philosophy, of which a theory of existential domains is the central part. This philosophical metatheory is the highest paradigm of philosophy, where paradigm is understood as a pattern in the Kuhnian sense. Whether or not a philosophical theory can stand on its own in a "high-level philosophical forest" can be decided by whether a unique ontology for it has been established.

In traditional Western philosophy, existence is partitioned into three basic existential domains:

God as objective idea; matter; and personal individual spirit or soul. The theory of these basic existential domains refers to these domains and their interrelations. As science developed, revealing the materiality of ostensibly divine nature, the concept of God gradually disappeared from the forefront of science and philosophy. Therefore, it is now more reasonable to define a corresponding ontological paradigm of Western philosophy as "existence $=$ matter + spirit", (excluding some doctrines in specifically religious studies), where "spirit" has the non-transcendental meaning discussed below.

In my research [1], I have shown that the recently developed Philosophy of Information partitions the existential domain again and suggests a new ontological paradigm: "existence = matter + information", where information consists of objective and subjective informational domains. In the scientific worldview corresponding to this paradigm, the world is constituted by matter-energy and information as its fundamental elements. Compared to the ontological paradigm of traditional philosophy, the new one reveals a new existential domain — the objective informational world—and redefines the nature of spirit in the sense of complex levels of informational activities [2].

\subsection{The Question of "Spirit"}

An introductory comment is necessary for the comprehension of this article pertaining to the term "spirit". There are two major meanings of the term "spirit": that of (1) an "objective" existing spirit which refers to God or an Absolute idea; and (2) a personal spirit of human beings, corresponding to the terms "mind" or "consciousness" in Western thought. In modern Chinese philosophical terminology, the term "spirit" can be used in both cases.

Both Chinese and Western materialists, of whom I am one, do not accept the existence of an objective spirit as usually defined. The so-called objective spirit, which does not exist in the real objective world, is only a creation of personal spirit. It is unnecessary to distinguish the two concepts of spirit in Chinese, but my use of the terms spirit and spiritual in this paper is exclusively in the personal, that is, immanent sense.

\subsection{A Philosophical Definition of Information: Direct and Indirect Being; Subjective and Objective}

In my philosophy of information, I give the following definition of information: "Information is a philosophical category indicating indirect being. It is the self-manifestation of the existing mode and status of matter (direct being)" [3]. Information can be distinguished into two fields: objective indirect being (objective information) and subjective indirect being (spirit, or subjective information). Thus, the formula mentioned above "existence = matter + information" can also be rewritten as "existence $=$ matter + objective information + subjective information $($ spirit $)=$ direct being + objective indirect being + subjective indirect being". Such a world view is a reflection of a fundamental change in the traditional world view of matter and spirit dualism, as it can describe the relation between matter and spirit as a process of mutual transition and transformation through the medium of information. The philosophy of information thus effectively dissolves the simple dichotomy of matter and spirit. 
If we investigate further the relationship between direct being and indirect being, we will see that the world of indirect being is derived from the interaction of the world of direct being, which is the world of the manifestation, presentation, mapping, representation or subjective reflection and subjective reform of the concept of nature, the world of the mode and status of direct being. A simple example can be given which illustrates the forms of beings and the correspondence relations between them. We can propose three kinds of modes of existence of the moon (or of any other real but not directly accessible object): the moon in the sky, the moon in the water (the moon in a reflecting surface) and the pattern of the moon in our brain. Those three kinds of moon respectively correspond to the direct being moon, objective indirect being moon and subjective indirect being moon. In fact, what the world of objective indirect being reveals is the relational aspect of the universal connection of objective things.

In my classification of the morphology of information, the information does not equal subjective "meaningfulness" or "significance". Beyond the subjective world there is also, following Sartre, an objective "in-itself information" world, but the subjective spirit is the "for-itself" form of information. Here, for-itself information refers to the information which is grasped by cognitive agents. A further form of information is "regenerated" information-new information that is processed and created by the thoughts of cognitive agents. The next level is that of social information, that involved in the interactions of cognitive agents. The essential points of my work on the philosophical nature and classification of information and the fundamental theory of information philosophy, published in Chinese, have recently become available in English [4-6].

\subsection{Outline of Paper}

In the next Section 2, I will discuss the informational turn taking place in science and philosophy. In Section 3, the convergence of science and philosophy under the impact of this turn will be discussed from the viewpoint of knowledge and universal reason. Section 4 goes more deeply into this convergence and the relation between science, philosophy and universal scientific rationality. Section 5 introduces the concept of a Unified Science-Philosophy of Information (USPI) and its incorporation of philosophy. In my final Section 6, the work of Y. X. Zhong in Information Science and mine in the Philosophy of Information are contrasted as exemplifying trends in current thought in China that are relevant to a potential USPI. Section 7 summarizes briefly the results of this study.

\section{The Informational Turn of Contemporary Science and Philosophy}

As I have discussed recently, at the Vienna Information 2015 Summit Conference, there are several theories of philosophical turns proposed by Western philosophers including the phenomenological turn, existential turn, axiological turn, praxiological turn and so on. The two most important are the turns from ontology to epistemology, and the consequent linguistic turn. However, these turns are concerned only with a shift of philosophical horizons, rather than any transformation at the highest level of metaphilosophical paradigm, and are not fundamental.

On the other hand, because of its universal character, information has a fundamental significance for the transformation of both philosophy and science, given its transdisciplinary properties and multiple levels and dimensions. It is the Philosophy of Information considered as metaphilosophy [7] that exemplifies the first fundamental turns in philosophy and science $[8,9]$. These "informational" turns are in fact not separate processes, but two sides of a single unified course of development of contemporary knowledge.

\subsection{Information Science}

For the nature of the subject in information science and other traditional disciplines, people usually only use labels like interdisciplinary subject, transdisciplinary subject, or comprehensive discipline to explain them. Even though these labels cannot be seen as inappropriate, yet just staying at the level of these labels is far from enough to reveal the significance and value of overall and radical 
reform that Information Science brings to traditional science. In essence, Information Science requires a transformation of the scientific paradigm, which will result in a brand-new scientific system which uses information theory as the predominant approach to cognition, forcing general information theory to be seen as interacting with traditional scientific systems. In this case, Information Science itself is a modern scientific system rather than a single field or discipline.

\subsection{Philosophy of Information as a Metaphilosophy}

My formulation of the concept of information as a basic category of philosophy defines the central role of information and information science in all relevant disciplines such as ontology and epistemology as well as in science. This is a metaphilosophical principle, since it has to do with the content of philosophy itself. Justification for my calling my Philosophy of Information a Metaphilosophy, "a highest philosophy", to be distinguished from all others, is its unique and universal character, its new worldview, as an informational conception of history, society, values, knowledge, science and technology.

A standard definition of the term metaphilosophy is a statement or set of statements about philosophy. I first note that a discussion of metaphilosophy requires a definition of both philosophy and the task of philosophy as well. As Brenner has pointed out, in that of Sellars, "the aim of philosophy is to understand how things in the broadest possible sense of the term hang together in the broadest possible sense of the term". My Basic Theory of the Philosophy of Information provides one basis for understanding both the metaphysical and epistemological dynamics of existence, that is, from where the properties of things come from that enable both them and the concepts of them to contrast, to conflict and ultimately to "hang together".

A theory of metaphilosophy that talks only in terms of categorial separation or distinction between elements, disciplines or methodologies in philosophy is that of Toulmin [10]. In my view, any such theory has a certain limited domain of validity, in which it is more or less adequate or appropriate to the philosophy in question. In an article in Chinese [11], I have given a broader role of metaphilosophy for information studies (and by implication for other disciplines): "Now, my research is still basically limited to elucidate the general basic theory of philosophy of information from the angle of a metaphilosophy. At such a level, there is a lot of work we should do to define the philosophical essence of information, the philosophical shape and form of information; the nature of the different levels of information; a philosophical measure of information; the relationship between information and various prior definitions of its scope; information ontology, information epistemology, information methodology; the evolution of the informational world; information in material and social evolution; informational sociology and psychology; informational esthetics: an informational theory of value; there are still have very abundant and a large number of branch issues in the each area field of that listed above". My view thus offers a novel dialectic perspective on philosophy, metaphilosophy and their recursive relation. It naturalizes this relation, eliminating any implied circularity, since it does not require the total independence of premises and conclusion of standard logics.

As indicated in the Introduction, my metaphilosophical view of information is not directed toward the codification of a Metaphilosophy of Information as yet another static discipline or body of knowledge. It is rather an attitude toward the positioning of an adequate Philosophy of Information as encompassing a critical component of all disciplines, beyond the scientific content specific to them. In this approach, metaphilosophy is not something "more abstract" than philosophy and it must be able to deal with the essential aspects of all disciplines and their theories. A metaphilosophical approach is essential to avoid unnecessary and misleading distinctions between disciplines and their informational aspects. One of the consequences is that the comprehensive nature of such a metaphilosophy, within a transdisciplinary paradigm, establishes the role of those involved as a socio-political role, involving them in the social and ethical aspects of the informational components of reality. 
The Metaphilosophy of Information as such requires further attention to the informational aspects of complex processes as a methodological necessity, in a process that I have called Informational Thinking. Informational Thinking (IT) refers to a way of grasping and describing the essential characteristics and attributes of things by reference to the structure and dynamics of the information involved in their evolution, from their historical origins to future possibilities and probabilities. This strategy involves something like a Husserlian bracketing of the details of any complex process to consider the ways in which information functions in its dynamics, as well as the dialectical relations between its logical elements. However, the difference between my theory and that of Husserl is obvious: the purpose of the original Philosophy of Information is to clarify the nature of the dual existence and dual evolution of material and information in the objective world, starting from the logic of the existence and dynamics of the natural human self. This phenomenology, unlike that of Husserl, does not have to be "naturalized", that is, brought into the domain of natural science (The naturalization of Husserlian phenomenology was the subject of a major 1999 study: Naturalizing Phenomenology. Issues in Contemporary Phenomenology and Cognitive Science. Eds. Jean Petitot et al. Stanford University Press, Stanford. My approach eliminates the arduous task of finding natural equivalents for Husserl's transcendental intuitions). It is already there, in the real processes involved in an individual's understanding at the level of the integrated object and subject, with internal and external interactions providing the necessary multi-level objective and subjective mediation. In this sense, all cognitive issues, especially informational values, valence and social evolution, have implied the use of Informational Thinking for their analysis. IT requires the abandonment of thinking in absolute material terms in traditional material while retaining its commonsense foundations. IT is basically a methodological concept that, via the definitions of carriers and codes of information, enables inferences to be made about the historical and potential or probable future states of an information system. IT dialectically unifies energy factors and informational factors, determinism and indeterminism, internal and external feedback processes, independence (autonomy) and interdependence. In fact, Informational Thinking is the Metaphilosophy of Information in other terms.

\section{The Intrinsic Unifying Convergence of Science and Philosophy}

\subsection{Knowledge and Universal Reason: The Basis of the Convergence of Science and Philosophy}

In the most general sense, we can view philosophy as an activity of seeking universal reason, while scientific observation and experiment have the characteristics of concrete perceptual activity. (For more details about this paragraph and the next see [12]). On the basis of this, philosophy and science have generally been considered as separate disciplines.

In fact, general reasoning and concrete perception should not be separated completely in any form of human cognitive activity. Human beings inevitably evaluate all kinds of sense data in the framework of reasoning. It is one of the obvious differences between human consciousness and the animal mind, as well as the ultimate ground of philosophy and science as an intrinsically unified knowledge system.

Science is essentially constituted by principles of universal rationality. For a discussion of scientific rationality in English, the reader is directed to the recent article in the Stanford Encyclopedia of Philosophy [13]). Those principles are not equal to direct narratives about facts of observation and experiment. They depend on certain concepts, rules and methods of abstract philosophical thinking to ascend from narrations of facts to principles of universal rationality. We can thus begin to see how philosophy is in science, and how science is in the rules of philosophical paradigms. There is an intrinsic, implied philosophical concept in any scientific universal rationality, which therefore can be viewed as the "offspring" of certain philosophical concepts and concrete narratives combining with one another. The unity of philosophy and science cannot be considered exclusively as an external join, but as an inner convergence as well. 
Most scientists believe that scientific theories are established on the basis of observed, experimental data and facts, the concrete perceptual characteristics of which define the concrete perceptual characteristics of science itself. Only if those data and facts are accurate will the scientific conclusions obtained from them be precise. However, have scientists considered seriously by what concrete means those data and facts are obtained and explained?

\subsection{Information and Cognition}

Human beings do not cognize the objective world directly. There are many complex kinds of intermediate relationships between cognition and the objects of cognition, as discussed in a paper in English [6]. In related research on the Philosophy of Information, I proposed a complex emergent theory which explains the occurrence of cognition in terms of five intermediate aspects: (1) an objective informational field; (2) a subjective physical structure; (3) a subjective knowledge structure; (4) subjective material instruments; (5) a subjective genetic-historical dimension.

In view of these five intermediate aspects, the phenomena seen directly in observation and experiment are not the "objective facts" themselves, but the macroscopic informational signs of "objective facts" remaining after transfer through intermediate structures. Accordingly, to draw valid scientific conclusions is possible only by explaining those signs. The corresponding explanations depend not only on the analysis of the experimental results of observation, with or without instruments, but also on the scientific theoretical paradigms applied to recognize those structures.

Thus, no kind of science can be determined solely by so-called concrete sense data. Scientific knowledge is the combined product of sense data and general reasoning. In this approach, philosophy can no longer be considered something transcendental, irrelevant to and outside science. I do not wish to conflate, that is, eliminate all distinctions between philosophy and science. Both have targets and methodologies that are unique to them, but mutual influence and interaction seems the correct term for the relation between them.

\subsection{The Content of Scientific Experiment}

During the process of scientific observation and experiment, the content observed by scientists through complicated instruments of observation is not the original status of any actual objects. In the macroscopic observation area which can be realized by human senses or simple instruments, the effect of information conversion and transformation happening via medium are still inconspicuous. However, such effects cannot be ignored in modern science; because of the observation of the universe which is beyond the macroscopic world and microscopic world we have to use very complicated scientific instruments which magnify such effects to a significant extent. In fact, the things which can be directly observed in scientific survey and experiments by scientists are some macroscopic marks: the trajectory and structure of point, ray, curve, colored tape or picture, left by the relevant information of "object fact" after transformed by intermediary apparatus, rather than the so called "object fact" itself. We have to give relevant explanations to the marks of these trajectories and structures, so that we can obtain a valid scientific judgment from them. These relevant explanations, however, not only rely on the analysis of the performance of observation instruments and apparatuses used by scientists, but also depend on the related scientific paradigm existing in the scientists' cognitive structure. Thus, between the "objective facts" (the observed objects) and the "scientific facts" (marks left by information transformation by instruments), between the "scientific fact" and the "scientific judgment" and between the "scientific judgment" and "scientific theory", there exist complicated intermediate relationships. Thus, in fact no kind of science can be determined by sensibility alone; science is by its nature a product of combining concrete sensibility and universal rationality. Better, sensibility and rationality are present in thought as conjugate variables of a kind, varying in reciprocal proportions between the limits of 0 and 1: philosophy is at one limit and science at the other.

In this way, philosophy is no longer transcendental, having nothing to do with science or being beyond science. Philosophy is something that is integrated into the science, working as a part of 
its organic composition, acting as its "soul in a metaphorical sense" and playing a core role in a scientific paradigm. By "soul in a metaphorical sense" I mean high-level cognitive approaches to acquiring, explaining and handling observational experimental materials, methods of normalizing them and the capacity for constructing scientific theories. Beyond perception, the worldview, epistemology, and methodological considerations on how to undertake scientific research, how to process experimental data are important concepts that are an intrinsic part of scientific activity. Additionally, the fact that science draws on hypotheses and abductions shows the most crucial and important effects, significance and values of philosophical (and logical) considerations and gives a creative intellectual pattern to its development.

Some may argue that mathematics is pure logic and does not need to include any observational end experimental materials to be valid. Actually, however, due to the fact that mathematics is a kind of theory studying the quantitative relation and spatial, structural relation between things, it never can avoid interpreting the relevant relationships in the real world, involving not only elementary and advanced mathematics, but also Euclidean and non-Euclidian geometry, fractal theory and chaos theory). Mathematics also refers to various logics and language systems for computer programming. The point worthy to notice is no more than the difference of idealization of exceeding actual quantity and space relationship obtained by diverse mathematical forms. Theoretical physics also cannot be constituted only by pure logic and idealistic speculation. Even diverse idealized experiments regarding quantum theory, relativity and cosmology in general also need to find their explanation and proof in the relevant real world [14].

\subsection{The Level of Universal Rationality: The Relative Mutual Definition of the Partition of Science and Philosophy}

Because all scientific disciplines are systematically constituted by universal principles, what establishes the differences between them is their degree of universal rationality, not the presence or absence of such rationality. In other words, science at whatever level of depth has a philosophical sense from which we can determine the approximate boundary between philosophy and science. The inner differences of levels or degrees of universal rationality define the hierarchy of philosophy and science.

There exist complex interactions of mutual effect and definition between the levels of universal rationality, which can be considered a bi-univocal relationship between them. In one respect, the lower universal rationality is the foundation on which the higher universal rationality is established, the latter being derived by abstracting, generalizing and summarizing the former; in the other respect, the lower universal rationality is the instantiation of a higher universal rationality in a concrete area, the consequence and the product of the higher universal rationality determining it.

The problem of the existence and nature of levels in philosophy has been the subject of much debate, to which Floridi has contributed, among others, with the concept of Levels of Abstraction [15]. He is reluctant to accept any theory that postulates ontological levels of organization existing independently of the level of abstraction at which they are conceptualized. In my view, however, levels of rationality correspond to real mental structures (processes) which are not static within a level and are subject to change via recursivity. If we take engineering as a "concrete" area, it is always subject to reflection about its existential and moral implications, which, hopefully, are taken into account in practice.

The dual characteristics of the lower and higher rationalities inevitably induce them to converge, again without conflation, that is, while maintaining essential differences in targets and methodologies as indicated below.

In this process, the higher universal rationality illuminates, constrains and controls the lower universal rationality, while the lower universal rationality not only embodies certain normative principles belonging to higher universal rationality at its own level, but also provides valid basic foundations for higher universal rationality from its own material contents and activities. 
The interactions between levels of rationalities will necessarily result in a holographic unified relationship of internal convergence, on which different degrees and levels of rationality are based. Holographic means here that they are mutually embodied, constrained and reciprocally defined.

Ordinarily, the higher-level system of universal rationality is called philosophy, and what underlies this system is called science. However, such a distinction of the disciplines of science and philosophy is not fully correct, because it implies that philosophy and science are disjunct. In fact, the absolute partition between science and philosophy is only present in a historical phase when neither of them has been adequately developed. Philosophy must not be detached from and override science; rather it should be considered a (natural) kind of science, since science is in complete accord with the outputs of correct rational thinking, and science should be a kind of philosophy.

Any subject of human knowledge is constituted by a certain proportion of concrete sensibility, that is, of science and of universal rationality, philosophy. The ratio of these two ingredients varies reciprocally from $0 \%$ to $100 \%$ [16].

\section{The Transformation of Science into Philosophy. The Critiques of Science by Philosophy. The Self-Critique of Philosophy}

\subsection{The Transition between Levels of Universal Rationality}

A true Philosophy of Science, which should obviously be grounded in science, thus cannot be separate from and supervene on science. The current dependence of philosophical development on scientific development indicates that science is the strongest and most basic driving force for the transformation of philosophy.

In general, new scientific concepts and principles that can reveal the nature of things and phenomena are always rationalities that are first proposed in certain narrow scientific domains and therefore have narrow functional areas of application. There exist, however, concepts and principles of a more universal character which can break through the initial narrow disciplinary limitations.

Such concepts or principles can transition to a higher level of universal rationality, and illustrate its most general aspects.

If the new concept and principle is not completely contrary to the old one, or there is just a small partial contradiction between them, then the old rational system will not change substantially or only be modified in small details. However, sometimes there is a situation where the new universal rationality conflicts with the fundamental universal rationality at the higher level, forcing the higher-level system to take one of the following two attitudes: (1) repel the new system to protect itself; (2) use the new one to change or replace the old contrary one to renew the entire general system of rationality. The former attitude is usually the one accepted by conservative theory, while the latter attitude might initiate a revolution at that level.

In the history of philosophy and science, the transforming effect of science on philosophy is obvious. Consider ontology: in ancient Greek philosophy, there was a theory of atomism, a world constructed by indivisible material particles. Later, from the point of view of classical mechanics, the world is constructed integrally by particles whose basic properties result from the interactions of forces. "Quality" was considered by modern materialists and physicists as the symbol of the existence of matter, and the "weight" of quality as the standard magnitude of measuring matter. In other words, materialist philosophers all conflated matter with "quality" in science and viewed it as the origin of the world. Next, matter-energy was shown to be a more basic form of reality than quality by electromagnetic field theory, relativity and quantum mechanics. This new development in science made traditional materialism lose its raison d'être, which led to corresponding transformations in philosophy, the emergence of modern energetics, a new realism and a new materialist philosophy.

Now, it is seen to be necessary to investigate the world and the things in it from an informational viewpoint, beyond that of matter/energy alone. The contemporary scientific worldview turns out to be an integral, complex informational theory and the scientific thinking turns out accordingly to be an informational thinking as well [1]. 
Following the middle of the last century, following the emergence and development of a basic Science of Information, the significance and value of an informational world at different levels of existence has appeared in stages. New developments in science challenged requirements for a dichotomy between the matter and spirit and subject and object of traditional philosophy, and resulted in the emergence of the contemporary Philosophy of Information. Based on the new "fruits" from the development of the Science of Information, the Philosophy of Information establishes new philosophical and scientific paradigms based on the dual existence and dual evolution of matter and information, which as noted not only brings about the first fundamental turn in philosophy, but also establishes the precondition for a Unified Science of Information.

Recent developments relevant to the problematic of unity have been well summarized by Jordi Cat in his article on the Unity of Science [17]. These can be read as avoiding any principle of "unity for the sake of unity". Cat notes several positive, anti-reductionist trends in the philosophy of science, for example in moving from dependence on concepts primarily from physics. Cat suggests that the concept of unity can have value at the practical level in science, to justify approaches and goals, and in philosophy to help choose what philosophical questions to pursue and what target areas to explore. Reference to the Unity of Science could be made to describe what science is to be considered by philosophy as authoritative.

\subsection{Exclusion of the Limit of Lower Universal rationality. The Critique of Science by Philosophy}

The transformation of philosophy is achieved by the transition from levels of scientific universal rationality, but this does not imply that philosophy is a passive participant in this process. In contrast, without the initiative in philosophy, the transformation of science to philosophy could not be achieved. Here, it is useful to emphasize another aspect of the relationship between philosophy and science: the critique of Science by Philosophy.

The universal rationality of science is of much greater universality and can surpass the narrow limits of the disciplines from which it was originally generated toward higher form of universal rationality. Hierarchical transition is a process of the self-sublimation of universal rationality, and the reconsideration or re-evaluation of the concept of a universal rationality itself. This higher universal rationality defines and processes the original lower general rationalities by taking them as objects of investigation. In other words, the higher universal rationality imposes its methodology on lower rationalities while generalizing, summarizing and assimilating the lower general rationalities, implementing a kind of philosophical critique in the process.

The fact that philosophy must enrich and develop itself through science, however, does not mean that philosophy is just a "vassal" of science. Philosophy has a critical role at its own level. In the development of the concepts of the unity of science and philosophy, it is inevitable to have to take into account aspects of the transformations effected on philosophy by science and critiques made of science by philosophy. In the process of the development of science and philosophy, the (partial) transformation of science to philosophy and the critiques by philosophy of science are clearly manifested.

In the second phase of the scientific revolution, after the acceptance of the achievements of electromagnetic field theory, relativity field theory and quantum mechanics revealed the more basic nature of energy as compared to matter in the real world, the idea of fighting against materialism with energetics occurred to some scientists and philosophers. They preferred to call themselves realists rather than materialists. In this situation, the transformation of science seriously challenged the older materialism explained by material substance, which indicates how the development of science can require that philosophy transform and develop itself. However, where the emergence of energetics induced philosophy to change depended on the critical function of philosophy itself. At that time, there were two different philosophical critiques: one was to consider the relationship of quality and energy in a mechanistic and replace materialism by energetics. Another critique was is to consider that relationship in a dialectical way, view them as different forms of objective reality, and accordingly reveal the material nature of objective reality by critical analysis in order to establish a new kind 
of materialism that could include both matter and energy. The explanatory principle of objective reality not only sublimates the concept of energy in science to the level of general philosophy, but it also makes possible a materialist explanation of energy and energetics by a philosophical critique in which the transformation of science to philosophy could be seen, and the general characteristics of the achievements of science could be sublimated into philosophical conceptions and theories as well [18]. The process by which the contemporary Philosophy of Information was established thus illustrates its dual effect: the transformation of science to philosophy and the critique of science by philosophy.

\subsection{The Problem of the Nature of Information}

As we know, the communicational theory of information of Shannon and the informational cybernetics of Wiener in 1948 both belong to the field of technological informational science. Wiener's suggestion [19] of an ontological meaning of information as different from matter and energy has led to many discussions and investigations of the philosophical problems of a Science of Information. These have taken the form of a search, by Eastern and Western scholars, for an interactive, realist theory of a Unified Science of Information (USI), based on the development of both the Science and Philosophy of Information (see Section 5 below). Recognizing the limitations of his initial theory, Wiener did try to emphasize the general philosophical character of information, discussing the nature of information from a philosophical view while considering information as negative entropy from a view of pragmatic informational theory. He had two famous ideas: one was that "information is information, neither matter nor energy". The other one was that "information is a name for the content of what is exchanged with the outer world as we adjust to it, and make our adjustment felt upon it" [20]. Although Wiener did not define what exactly information is directly, he thus emphasized the independent value and meaning of information compared to matter and energy., while seeing the necessity of considering information from "the exchanged content" point of view as well.

However, these explanations of information remained at the functional level of technological pragmatism. Until now, their definitions of information are still the basic doctrines in scientific circles: information is indetermination that has been removed (Shannon); information is negative entropy (Wiener).

Obviously, both of these are just relative and quantitative definitions of information made from a consideration of the sender's unidirectional relation to the receiver. Although they have pragmatic value in the fields of communication and cybernetics, they do not reveal the general nature of information.

Scientists and philosophers, who missed the critical aspects of these definitions, adopted the method of simple analogies of the theoretical conceptions and the disciplinary characteristics related to pragmatic informational science and technology and traditional philosophy for the explanation of information. Several research approaches to studies of information problems can be listed: the computational, the information ethical, the communication informational, the information cognitional, the sign informational, the information phenomenological, and so on. However, because these approaches are dependent on a given concrete philosophy or science, they are consciously or unconsciously constrained by the narrow and limiting characteristics of their original theories and disciplines. Accordingly, these theories do not reveal the truly unique and revolutionary significance of informational considerations. A Unified Information Theory founded on them cannot be considered as a higher Science of Information, let alone a general Philosophy of Information, a Unified Science of Information, or, in the formulation I now prefer, a Unified Science-Philosophy of Information.

The transformation of philosophy by science thus cannot be achieved automatically by counting on scientific successes in themselves, but depends on relevant critiques of science by philosophy. This is a two-sided interactive process, to which both science and philosophy contribute. Thus, in his pioneering work on the Philosophy of Information in the West, Luciano Floridi has called the impact of information science and technology an informational revolution [21]. His proposal of an "informational ontology" correctly critiques the limited, computational concept of a digital ontology. 
However, as the I have pointed out, Floridi has not addressed the core problem of the nature of information and the impact of the philosophy of information on philosophy in general.

One important contribution to the field that Floridi has made is his concept of Informational Structural Realism (ISR). Thus, Floridi argues, for example, in [15] that digital ontology, according to which the ultimate nature of reality is digital or computational, should be carefully distinguished from informational ontology, according to which the ultimate nature of reality is structural [22]. Floridi avoids the Boolean digital vs. analogue dichotomy in favor of ISR, according to which knowledge of the world is knowledge of its structures. The most reasonable ontological commitment favors an interpretation of reality as the totality of its structures, energetic entities, dynamically interacting with one another. In my view however, the Floridi limited ontology fails to capture the evolution of real informational processes.

Floridi's position is that the ultimate nature of reality is informational, mind-independent and constituted by structural objects that are neither substantial nor material (they might well be, but we have no need to suppose them to be so). The Logic in Reality of Brenner [23] offers a principled basis for saying that they are and suggests the logical rules they follow. In the mutual transformation process of matter (mass-energy) interaction in the nature itself, the information exhibiting the corresponding process and quality is intertwined in the interactive matter by the way of spatio-temporal conversion and mutual mapping and transformation among matter. Consequently, the information world reveals the matter world that has been created, and this information world is specifically embedded in the relevant structure of matter world. Logic in Reality describes the movements in nature such that the whole world and everything in the world are dualities of matter and information. According to this idea, we can say that Logic in Reality [7] may become one of the theoretical foundations of for unifying information science and information philosophy. I had completely independently written a book discussing logics of nature which presents an intensive investigation of the relevant questions [24].

The critical aspect of information, to which Hofkirchner and others are now turning, is its dualistic relation to the energy of which it is constituted. In the view of Brenner as well as me, it is this duality or dualism that is the actual "driver" of informational processes.

\subsection{Meaning from an Informational Standpoint}

A key issue in philosophy is the emergence of meaning in human activities, which I propose can be looked at from an informational standpoint. First, two kinds of epistemological theories of meaning can be identified: (1) a semantic theory which assigns semantic contents to expressions of a language; and (2) a foundational theory of meaning which states the facts in virtue of which expressions have the semantic contents that they have. My conception of meaning is ontological and foundational. According to Aristotle, philosophy is a doctrine about "existent being", so the primary problem faced by philosophy is "What does exist?", the domains of being, and the relation between them. It is how this question is answered that defines the fundamental nature of philosophy, as well as stipulates the basic approaches and methods of dealing with the problems in other fields. Therefore, the ontological doctrine of a specific philosophical system becomes the criterion for judging the nature of that system and deciding whether it is able to stand firmly at the level of meta-philosophy.

Human cognitive activities are involved in processes of the mutual selection and matching, reorganization and reconstruction, creation, according to a non-deterministic model, of new subjective information processes. I designate as teleological (in the Deacon sense) or purposeful information that created by human beings to achieve or insure the success of practical activities. Thus, human activities of material production, from my informational standpoint, imply the process of planning to implement purposeful, structural information to create material objects, effect actions, etc. I am particularly concerned about the way in which new information is created in the recombination of available modes of communication between human beings. In the process of transmission of information from sender (subject) to receiver (object), the teleonomy of the subject implies that its information will be realized in the object. Meaning emerges in this process that I propose follows both the dialectic principles of Logic in Reality [23] and the Teleodynamics of Deacon [25]. The true definition of meaning is then new 
content in the information. Once high-level information activity patterns are created, they acquire the properties of meaning and value for a person by a process of self-reference, which adds a new element to the person's entire information activity system. Of course, meaningless information involved in the relations between objective things, their mappings and their presentations is widespread in nature. This part of information I call "in-itself" information, for which there is no cognitive interpreter.

\subsection{The Constructive Transformation of Advanced Universal Rationality. The Self-Critique of Philosophy}

The critique of philosophy has a dual significance: the critique not only aims at specific boundary of science, but also points at philosophy itself. The purpose of a critique to science from philosophy is to eliminate a certain parochialism and the limitations of some category theories. The criticism to itself from philosophy is to break down a facet which is ossified, dogmatic, outdated and conservative. Philosophy has always had a two-sidedness: conservativeness and criticalness, sluggishness and activeness, backwardness and vision. Nevertheless, philosophy also is the spirit of the era and cannot lag behind it in the long term. The development of science and society demands that philosophy exhibit sufficiently its positive characteristics, while recognizing that, as for all real systems, contradictions and regressions will never be totally absent. In other words, philosophy, that is, philosophers, have to have the ability for self-criticism to develop and transform themselves.

The transition of a lower universal rationality to a higher level referred to above and the critiques of philosophy by science proved that philosophy is an open system, which needs "information" from outside. However, this information from outside must accept the methodological primitives of philosophy itself, namely choice and critique. Only when it (information) is integrated critically into the structure of philosophy can information be assimilated to the content of philosophy. As a result of this assimilation and regulative self-critique, philosophy can transform itself naturally by itself. In this process of assimilation, the following dual effects are achieved: on the one hand, external information is critiqued by philosophy; on the other, because that kind of critique changes the original construction of philosophy-in-itself, philosophy as a whole is critiqued as well. If the change of construction is comprehensive and if that critique acts on the most basic concepts and principles that represent the highest paradigm of philosophy, a fundamental transformation is possible.

The contemporary Philosophy of Information reveals the problems that affected the development of philosophy in regard to the above critical issues. In fact, for a long time, to explain the nature of information, there had been a tendency to use not only the simple analogies discussed above, but also analogies from related theories and traditional conceptions of philosophy.

For example: "information is a property of matter"; "information is a way of existence of matter"; "information is an existing state of matter"; "information is a character of spiritual entity"; "information is the externalization of movement"; "information is an interactive concept of matter"; "information is reflection"; "information is meaning", and so on. These all tried to match information to simple traditional philosophical concepts. Far from revealing the new, unique and universal character of information, they castrated it, eliminated its comprehensive and fundamental significance for transformation and value, leaving it in the decayed cage of the old paradigm of traditional philosophy. It is impossible to establish a Philosophy of Information in accordance with and reflecting the spirit of the time and its innovative significance by way of analogies. As von Bertalanffy pointed out in relation to systems, "analogies are scientifically worthless" [26]. This is why the work of only a few philosophers has been relevant to the establishment of either a systematic Philosophy of Information or a Unified Science-Philosophy of Information.

As long as the constraints of the traditional philosophical paradigm continue to be used, complete with their traditional philosophical concepts, theories and methods, the emergence of any kind of truly new philosophy will be difficult and very long in coming.

The general characteristics of information transcend the basic premises and theoretical structure of traditional philosophy. A Philosophy of Information that truly shows these general characteristics establishes the critiques that philosophy makes of science, and the critiques that philosophy makes of 
itself as well. To repeat, the new ontology of the Philosophy of Information changes the basic doctrine of traditional philosophy: "existence $=$ matter + spirit" into "existence $=$ matter + information (spirit being only a complex form of information)". Thus, the subjective-objective relationship of traditional philosophy is transformed into a more complex interactive relationship that includes the multiple informational intermediary activities of the spiritual (cognitive) subject and object. This transformation realizes the fundamental innovation of philosophical ontology and epistemology, philosophical evolution theory, philosophical value theory and philosophical methodology as well. Due to the dual-critical process of the philosophical critique of science and philosophy itself, the Philosophy of Information achieves a comprehensive transformation of traditional philosophy, which results in the first fundamental turn in history of philosophy, as discussed in Section 2 [27].

\section{A Unified Science of Information "Upright between Heaven and Earth"}

As a result of establishing the fundamental role of information in the existential domain, the Philosophy of Information provides a kind of dual-existential and dual-evolutionary theory of matter and information which describes information as a general phenomenon existing in everything in the cosmos. That leads to the acknowledgement of the dual dimension of matter and information in all forms of research. Because the lack of an informational dimension in traditional philosophy and science, it is necessary to transform them completely to take into account the new scientific paradigm provided by the current Science and Philosophy of Information. By means of that transformation, all scientific and philosophical domains become involved in an integrating, developing trend of paradigm transformation, which I have called the "informational scientification of science" [28].

The current interaction and convergence of the Science and Philosophy of Information represents a fundamental and basic path for the development of scientific and philosophical knowledge. This "philosophization of science" and "scientification of philosophy", anticipated in the progression from ancient philosophy to modern science and philosophy, now represents a completely new way of thinking that is that distinct from that of the contemporary Western philosophy of consciousness. It resists an absolute separation between science and philosophy and establishes interactive, mutually defining feedback loops between science and philosophy which emphasizes their interrelation.

With the emergence of this completely new trend, philosophy and science are now facing a new situation, which might be considered as a rationale for establishing a general Unified Science of Information, better, a Unified Science-Philosophy of Information that would include all the domains of philosophy, science, technology and mechanics. The idea of establishing first a Unified Science of Information was initiated by a group of European scholars in the 1990s. Since then, from different levels and disciplinary viewpoints, many scientists and philosophers from all over the world have made efforts in that direction including A. D. Ursul and Konstantin Kolin from Russia; Pedro Marijuán, Wolfgang Hofkirchner, Søren Brier, Rafael Capurro and Joseph E. Brenner from Europe; Yi Xin Zhong, Ming Li, Changlin Liu, Litian Shen, Xianhan Luo, Dongsheng Miao, Kang Ouyang, Xueshan Yan and I from China; and Luciano Floridi, John Collier and Albert Borgmann from other countries.

This research suggests the independence and universality of the informational world. It anticipates and is the precondition for the establishment and development of a needed new modern paradigm for science and philosophy, a new worldview in which Unified Science-Philosophy of Information would have a central role.

The informational world, of course, is not independent of the material world. It is the complexity of its dual aspects of information-as-energy and information-as-meaning that is the source of the difficulties in its comprehension. However, they have different modes of existence, and information flows in its own, unique mode according to its own rules. In this sense, information is relatively independent of the material world, while not being separate from it. Logic in Reality provides the framework for the interactive dialectic relation between them. 


\section{The Disciplines of Information Science}

Elsewhere, I have proposed a model of a potential Unified Science of Information classified according to six major levels: the Philosophy of Information; a General Theory of Information (GTI); Regional Informatics, in which the basic principles of the GTI are collated in three major disciplinary sub-groups: natural informatics, social informatics, cognitive informatics); Category Informatics; Branch informatics (several branches); and Engineering Technological Informatics [29]. In the meantime, this classification has become somewhat less relevant and useful at a practical level.

In the West, the concept of a GTI was first stated explicitly by Mark Burgin [30], later expanded and developed in a major book [31]. The concept of a Unified Theory of Information has been developed most completely by Wolfgang Hofkirchner [32,33].

In contrast, a Unified Science of Information (USI), to use a Chinese metaphor, would be a disciplinary system "upright between heaven and earth" that is, including all human knowledge levels from philosophy to science to engineering technology. Such a Unified Science of Information would favor further convergent integration of science and philosophy, toward a Unified Science-Philosophy of Information. In this integration, the philosophical sense of the Science of Information and the scientific character of the Philosophy of Information would be fully present. Thus, the Philosophy of Information could be viewed as a part of a general Science of Information, and the Science of Information as achieving its real unity by its foundation in the general principles of philosophy. In this vision, the Unified Science-Philosophy of Information is the scientific basis of a general Philosophy of Information, and the Philosophy of Information is the general theoretical precondition of a unified and unifying Science of Information.

In my opinion, the establishment of a Unified Science-Philosophy of Information and the mature development of a Philosophy of Information should be a process of convergence, two sides of a new and integral developing pattern of contemporary human knowledge.

\section{Information Science and Philosophy in China: A Comparison of Wu Kun and Yi Xing Zhong}

In China, there is a kind of natural understanding and interactive relationship has emerged in joint discussions of the Science of Information proposed by Yi Xing Zhong and the Philosophy of Information proposed by myself. The disciplines are different in approach but equally satisfactory in their conclusions.

In October 2014, the tenth forum of the Journal Philosophical Analysis: entitled "A National Conference on the Philosophical Spirit of the Informational Era" was held in Xi'an by the editorial department of Philosophical Analysis, the International Center for the Philosophy of Information in Xi'an Jiaotong University and the Research Society of Natural Dialectics in Shaanxi province. Zhong discussed five aspects of his understanding of that relationship in his conference paper entitled "The Consideration of the Philosophy of Information from a viewpoint of the Science of Information" [34]. The detailed comparison of our views is outlined below.

\subsection{Characteristics: Harmonious But Different}

My Philosophy of Information is broad and general, while Zhong's Science of Information is deep and systematic. They both capture key problems in their respective ways and answer the basic questions such as "what is information?" and "what is the rule of movement of information". Their conclusions have their own focal points and respective characteristics, but they prove each other as well.

\subsection{The Partition of Existence: Philosophy Opens the Way}

As we have seen, traditional philosophy states: existence $=$ matter + spirit. My Philosophy of Information keeps the term "spirit" but gives it a new reading in terms of information. Zhong's Science of Information maintains that "information is a kind of universal existence in the fields of 
nature, human society and spirit". This supports the preferred interpretation of "existence $=$ matter + information" in my Philosophy of Information.

\subsection{A Basic Concept: Different Melodies Played with Equal Skill}

My basic definition of information is that "information demonstrates by itself the existential mode and state of matter". Zhong's Science of Information establishes a hierarchy of definitions of information. Ontological information as an ultimate source of all levels of information is defined as: "the apparent way in which things change", where "things" are material or spiritual.

Zhong's and my theory possess their own philosophical and scientific characteristics with different words and phrases, but their connotations are consistent: "appear" has the same meaning as "show"; "a state of movement and mode of change" is virtually equivalent to "the existential mode and state of matter".

\subsection{Informational Epistemology: Enhancing Each Other's "Beauty"}

My Informational Epistemology proposes five levels of informational activities involved in the process of human cognition: in-itself activities of information, perceptual intuition and cognition of information, memory and storage of information, subjective creation of information, social realization of information. He discussed the holographic top-down controlling and the progressively increasing bottom-up relations from between those five levels, as well as an integrative participating and mutually transforming relation. Obviously, this is a comprehensive discussion of principle, a complete analysis from informational ontology to informational epistemology. Zhong's Science of Information [35] defines information as "form (grammatical information), meaning (semantic information), effect (pragmatic information) of states of movement state and mode of change effected by cognitive subjects". He calls this trinity "complete information". Based on this, an "informational transforming rule" reveals the mechanism for going from objective "ontological information" to subjective "intelligent strategy and action". It is interesting that the "informational transforming rule" in the Philosophy of Information and the "informational analysis of levels" in Zhong's work enhance each other's meaning "beauty". They are "beautiful" theories. The Philosophy of Information illustrates the broad principles of Informational Epistemology, while the Science of Information explains the deep mechanism of informational transformations; Zhong and I thus hold the same view.

\subsection{The Concept of "Informational Intermediaries": Respective Discoveries}

As mentioned above [6], my informational epistemology views the human cognitive process as virtual informational activities carried out via multiple intermediaries, which eliminates any mystery about the interactive process occurring between subject and object.

Zhong considers that informational effects provide an intelligent strategy to recognizing and transforming the world for human subjects through a series of "informational transitions" from ontological information to epistemological information, then to knowledge, to basic consciousness, to emotion, to reason, to intelligent strategy, finally to intelligent action. The objective is to realize the benefit of both the subjective and objective worlds and improve the existing and developing environment. Therefore, an "informational transforming rule" and an "informational virtual intermediary construction" reveal the informational mechanism of subjective and objective interaction on the levels of science and philosophy respectively. They both make discoveries and prove and supplement one another.

Zhong said in the last part of his paper: "It stretches the imagination that the Science and Philosophy of Information are so harmonious with one another while their investigators carry out each other's researches independently". In my opinion, in Chinese research, it is not a coincidence that the studies on the Science and Philosophy of Information are naturally concordant, interactive, illuminating and different in approach but give equally satisfactory results. Firstly, it is the reflection 
of the universal character of information; secondly, it is the reflection of the unity of philosophy and science; thirdly, it is the reflection of the communication between and convergence of research in philosophy and science, on which a Unified Science-Philosophy of Information should be based; fourthly, it is the reflection of Chinese scholars' persistence in a new use of dialectical thinking.

For a long time, the dogmatic aspects of the textbook system of Chinese dialectic materialistic philosophy were serious, but if one does not stick to its dogma, and adds explanations from complexity thinking, one can then see the true sense of dialectics as a methodology. Ways of convergence of informational thinking, systematical thinking and complexity thinking are then possible, endowing science with the characteristics of what I prefer to call dialectical realism and philosophy with characteristics of complexity. By doing this, the definition and impact of philosophy on science, the transformation and reconstruction of science into philosophy, and the critical development of philosophy itself can be demonstrated.

To summarize, this dialectical and integrative process in science and philosophy is in my view the general mode of Chinese development of the Science and Philosophy of Information: the informational philosophization of informational science and the informational scientification of informational philosophy. Here, it is not only a transformation and sublimation of science, but also a transformation and sublimation of philosophy.

\section{Conclusions}

In this paper, I have shown how the incorporation of the existential properties of information in philosophy leads to the convergence of science and philosophy in general and to an emerging Unified Science-Philosophy of Information (USPI). The USPI is thus a highly complex metaphilosophical system for organizing and discussing knowledge at the interface between science and philosophy. I believe we are witnessing the emergence of a new system of science, a metascience in a complex, dynamic reciprocity with philosophy that amounts to a paradigmatic revolution in thought. However, much work remains to be done to make the tools offered by a Unified Science-Philosophy of Information capable of being used constructively and routinely.

The achievements of science and philosophy in China [12] as well as the rest of the world have brought new hope for establishing such a Unified Science-Philosophy of Information. In view of the potential benefits to society, the establishment and healthy development of such a new philosophical conception of knowledge seems desirable. This paper is my proposed contribution to such a development.

Acknowledgments: I thank Joseph E. Brenner, Vice-President-Inter- and Transdisciplinarity of the International Society for Information Studies (IS4SI), Vienna and Associate Director of my Center for the Philosophy of Information in $\mathrm{Xi}^{\prime}$ an for his comments and suggestions regarding this manuscript.

Conflicts of Interest: The author declares no conflict of interest.

\section{References}

1. Wu, K.; Li, P. Scientific Evolution: The transformation of the scientific worldview and way of thinking. J. Chin. Renmin Univ. 2008, 3, 41-46. (In Chinese)

2. Wu, K. The Partition of the Existent Field. Sci. Dialect. Mod. 1986, 2, 32-33. (In Chinese)

3. $\mathrm{Wu}, \mathrm{K}$. The philosophy of information classification. Potential Sci. J. 1984, 3, 33-35. (In Chinese)

4. $\mathrm{Wu}, \mathrm{K}$. The Essence, Classification and Quality of the Different Grades of Information. Information 2012, 3, 403-419. [CrossRef]

5. Wu, K. The Development of Philosophy and Its Fundamental Informational Turn. Information 2015, 6, 693-703. [CrossRef]

6. Wu, K.; Brenner, J.E. An Informational Ontology and Epistemology of Cognition. Found. Sci. 2015, 20, 249-279. [CrossRef]

7. Brenner, J.E. Wu Kun and the Metaphilosophy of Information. Int. J. Inf. Theor. Appl. 2011, 18, 103-128. 
8. Wu, K. The Partition of the Existent Field and the "Whole New" Sense of the Philosophy of Information. Hum. J. 2013, 5, 1-6. (In Chinese)

9. $\mathrm{Wu}, \mathrm{K}$. The Interaction and Convergence of the Philosophy and Science of Information. In Proceedings of the 2nd International Conference on the Philosophy of Information, Vienna, Austria, 6 June 2015.

10. Toulmin, S.E. Knowing and Acting: An Invitation to Philosophy; Macmillan: New York, NY, USA; London, UK, 1976.

11. Wu, K. On the Relation of Science and Philosophy. Sci. Technol. Dialect. 2004, 1, 1-3. (In Chinese)

12. Wu, K. Philosophy of Information-A New Spirit of the Time; Shaanxi Normal University Press: Xi'an, China, 1989. (In Chinese)

13. Matheson, C.; Dallmann, J. Historicist Theories of Scientific Rationality. In The Stanford Encyclopedia of Philosophy (Summer 2015 Edition); Edward, N.Z., Ed.; Stanford University: Stanford, CA, USA, 2014. Available online: http://plato.stanford.edu/archives/sum2015/entries/rationality-historicist/ (accessed on 29 August 2015).

14. $\mathrm{Wu}, \mathrm{K}$. The crisis of philosophy and the informational turn of philosophy. J. Xi'an Jiaotong Univ. 2014, 1, $2-4$. (In Chinese)

15. Floridi, L. The Philosophy of Information; Oxford University Press: Oxford, UK, 2011.

16. Wu, K. The Philosophy of Information: Theory, System and Method; The Commercial Press: Beijing, China, 2005; Volume 266, pp. 27-29. (In Chinese)

17. Cat, J. The Unity of Science. In The Stanford Encyclopedia of Philosophy (Winter 2014 Edition); Edward, N.Z., Ed.; Stanford University: Stanford, CA, USA, 2014. Available online: http://plato.stanford.edu/archives/ win2014/entries/scientific-unity/ (accessed on 13 April 2015).

18. $\mathrm{Wu}, \mathrm{K}$. The development of philosophy and its fundamental turn from the viewpoint of an informational world. J. Chin. Renmin Univ. 2014, 3, 72-78. (In Chinese)

19. Wiener, N. Cybernetics; Hao, J., Translator; Science Press: Beijing, China, 1963; p. 133. (In Chinese)

20. Wu, K. Philosophy and Turns of Philosophy: Review of the Uniformity of Internal Integration between Science and Philosophy; People's Publishing House: Beijing, China, 2014; Volume 3.

21. Floridi, L. The Fourth Revolution: How the Infosphere is Reshaping Human Reality; Oxford University Press: Oxford, UK, 2014.

22. Floridi, L. Against Digital Ontology. Synthese 2009, 168, 151-178. [CrossRef]

23. Brenner, J.E. Logic in Reality; Springer: Dordrecht, The Netherlands, 2008.

24. Wu, K. The Logics of Nature; Northwest University Publishing House: Kirkland, WA, USA, 1990.

25. Deacon, T.W. Incomplete Nature: How Mind Evolved from Matter; W.W. Norton \& Company: New York, NY, USA, 2012.

26. Von Bertalanffy, L. General System Theory; George Braziller: New York, NY, USA, 1969.

27. Wu, K. Objective Reality, Substantial Materialism, Energetics and the Non-Substantial Trend of Materialism. J. Xi'an Jiaotong Univ. 2004, 2, 69-75. (In Chinese)

28. Wu, K. The basic problem of philosophy and its fundamental turn. J. Hebei 2011, 4, 11-21. (In Chinese)

29. Wu, K. The Informational Scientification of Science. Qinghai Soc. Sci. 1997, 2, 53-59. (In Chinese)

30. Burgin, M. Information theory: A multifaceted model of information. Entropy 2003, 5, 146-160. [CrossRef]

31. Burgin, M. Theory of Information; World Scientific: Singapore, 2010.

32. Hofkirchner, W. How to achieve a unified theory of Information. Triple C 2009, 7, 357-358.

33. Hofkirchner, W. Emergent Information: A Unified Theory of Information Framework; World Scientific: Singapore, 2013.

34. Zhong, Y.X. Information Science and Its View of Information Philosophy. Philos. Anal. 2015, 1, 17-31. (In Chinese)

35. Zhong, Y.X. Unity-Based Diversity: System Approach to Defining Information. Information 2011, 2, 406-416. [CrossRef]

(C) 2016 by the author; licensee MDPI, Basel, Switzerland. This article is an open access article distributed under the terms and conditions of the Creative Commons Attribution (CC-BY) license (http://creativecommons.org/licenses/by/4.0/). 